\title{
Assessment of Knowledge Retention Ability of Undergraduate Medical Students
}

\author{
Farhan Muhammad Qureshi, Muhammad Abdul Azeem, Mehwish Ejaz, Minal Marvi, \\ Sana Soomro, Layla Hasina, Shanila Khan
}

\begin{abstract}
BACKGROUND: Being a natural phenomenon, the knowledge learned by students is quickly forgotten. However, various factors are pertinent for one's memory and knowledge retention ability. This ability is not investigated earlier among pass and fail students of a particular exam.

OBJECTIVES: To determine and compare short term memory and Knowledge retention ability among pass and fail students of mid-term exam.

METHODS: 103 first-year MBBS students were examined in 3 cycles after result of mid-term examination announced. These cycles consisted of 2 components related with short term memory $\left(1^{\text {st }} \& 2^{\text {nd }}\right.$ cycles $) \&$ knowledge retention ability $\left(3^{\text {rd }}\right.$ cycle) with one week duration apart.

RESULTS: Class attendance of pass, fail and absentees groups demonstrated statistically significant $(P<0.0005)$ difference among them being in the order of pass $>$ fail $>$ absentees and significant correlation with marks obtained. A comparison between short term memory \& knowledge retention ability also demonstrated statistically significant $(P<0.0005)$ difference.

CONCLUSION: The quality of learning positively correlates with the class attendance. Short term memory and knowledge retention abilities are significantly better in pass students and statistically correlate with each other. Regular conduct of such tests is suggested to assess short term memory \& knowledge retention ability so that appropriate methods to enhance these can be adopted.
\end{abstract}

KEY WORDS: Medical Education; Undergraduate Education; Short-term memory; knowledge retention; learning ability; class attendance.

This article may be cited as: Qureshi FM, Azeem MA, Ejaz M, Marvi M, Soomro S, Hasina L, Khan S. Assessment of Knowledge Retention Ability of Undergraduate Medical Students. J Liaquat Uni Med Health Sci. 2017;16(02):126-30. doi: 10.22442/jlumhs.171620520

\section{INTRODUCTION}

Forgetting is ubiquitous as human memory is imperfect. It happens regardless of the nature of the material being taught, regardless of the age or background of the learner ${ }^{1}$. Students at every educational level are challenged by an ever-growing amount of material to review and an ongoing imperative to master new material ${ }^{1}$. Teachers rightfully focus their efforts on helping students to acquire new knowledge and skills, but newly acquired information is vulnerable and easily slips away from the memory ${ }^{2}$. Memory is the mechanism that allows us to retain and retrieve information over time ${ }^{3}$. Short-term memory (STM) contains our moment-to-moment conscious thoughts and perceptions and Long term memory (LTM) is the semi-permanent memory store, which endures for a lifetime and aids us in learning new information ${ }^{3}$. Working memory (WM) is a set of mechanisms that underlies STM and also communicates with LTM. The term "working memory" is defined as a person's ability to temporarily hold and manipulate information for cognitive tasks performed on a daily basis ${ }^{4}$. It is a very useful measure of a student's capability to acquire new information ${ }^{5}$.

Testing in medical education has largely served as an instrument of assessment ${ }^{6}$. It is a powerful mean to improve learning and knowledge retention not just its assessment. Later, it also enhances retention, to a phenomenon known as the testing effect ${ }^{7}$. In many circumstances, such as during lecture of a particular course in medical college, tests are given infrequently (often just once or twice a semester) and are generally perceived as a bother by faculty and students alike ${ }^{y}$. However, there is not a single agreed-upon measure of knowledge retention ability (KRA), but a number of different means, which may not always yield equivalent results ${ }^{8}$. In terms of the instructional approaches, the frequent memory tests are powerful vehicles for improving long-term retention ${ }^{8,9}$.

It is therefore, hypothesized that students who attend classes regularly have better memory, good in learning, achieve higher marks and have better knowledge retaining ability. Hence, the objective of present study was focused on the mental capability of medical students in terms of KRA by testing STM in 
3-cycles to determine and explore the following:

- Relation between class attendance and obtained marks of a test.

- Short term memory and knowledge retention ability among pass \& fail students in a test.

- A correlation between STM \& KRA.

\section{METHODOLOGY}

\section{a) Participants}

The entire class of first-year MBBS students $(n=103)$ of UMDC Batch 2014, who earlier went through midterm exam and declared either passed, fail or absent.

\section{b) Material}

Thirty questions were selected from the subject of Physiology, displayed on multi-media screen, one question at a time followed by the display of its correct answer, and the students were allowed to self-assess as per score sheet provided.

\section{c) Design}

This observational study was conducted over 6 months (May to October 2015) at Department of Physiology, United Medical \& Dental College (UMDC) Karachi, Pakistan. Ethical approval by the ethical research committee of UMDC and informed consent was also taken. Study design comprises of 3-cycles. In Cycle 1, 30 questions were displayed one by one followed by their correct answers and self-assessment scoring (SAS).After $5 \mathrm{~min}$, in Cycle 2 same 30 questions were repeated to assess STM for both the pass and fail group of students. After a week, in Cycle -3 once again same 30 questions were given but as best choice questions with 5 options, followed by the display of their correct answer and self-scoring.

\section{d) Procedure}

At the start of this test, the pass, fail and absent students of mid-term examination were briefed about: a) objectives of test b) 3-cycles of test to be conducted in 2-sessions, c) importance of retrieval power of memory, d) self-assessment test. They were advised to be honest in marking, " 1 " for the correct answer and "0" for the wrong answer. The memory test was conducted in 2-sessions having 3-cycles by the following procedure: The STM test began with the session-1 by conducting 2-cycles of self-assessment tests. The cycle-1 started to display 30 questions (duration $30 \mathrm{Sec}$ for each question) with subsequent answers on multimedia for $5 \mathrm{Sec}$ each. The cycle-2 was conducted after a brief period of $5 \mathrm{mins}$ to assess the STM of these students by using the same procedure. After passing a week, the KRA test was conducted as cycle-3. In this cycle, the students were given a multimedia based self-assessment test (SAT) but now questions are converted to best choice questions (SAT- 5 option BCQs) encompassing the same 30 questions displayed in cycle $1 \& 2$. Each of these
BCQs and their answers were also displayed one by one for $30 \mathrm{Sec}$ and $5 \mathrm{Sec}$, respectively. In between display of individual $B C Q$ \& its answer students brain stormed for correct answer and then on display of answer they self-scored on the score sheet provided. The statistical analysis of the data regarding this study was done by applying ANOVA, student's t- test and Pearson correlation using SPSS V-22 and XL V-2010.

\section{RESULTS}

\section{a) Mid-Term Test}

A comparison of class attendance and marks percentage obtained by first year students in mid-term test, categorized as pass and fail groups has been presented in Table I. Accordingly,103 students appeared in mid-term test. Moreover, out of the appeared students only 48 were able to pass examination while 55 students were declared fail, representing pass to fail ratio of 0.87 .In order to assess the relation between exam attendance and marks obtained, Table I also demonstrates that passed students who were $42 \%$ of the total, attended $82 \%$ of the total classes and obtained an average of $63 \%$ marks in mid-term exam. It is interesting to note that the class attendance of pass and fail groups demonstrated statistically significant $(P<0.0005)$ difference among them.

Pearson's correlation was determined to find any relation between the percentage of attendance and percentage of marks related with mid-term examination. The result presented in Table I also demonstrates statistically significant correlation among them.

\section{b) STM \& KRA}

The statistical comparison of the data belonging to the students appeared in STM $\left(1^{\text {st }} \& 2^{\text {nd }}\right.$ Cycle $)$ and KRA $\left(3^{\text {rd }}\right.$ Cycle) tests has been presented in Fig No.I. These tests were performed to compare the ability of 2 categories of students, who were declared, pass and fail in their mid-term examination. Results showed that the marks percentage of STM test was found higher in the pass group as compared to the fail group being $60 \& 52 \%$ respectively; the marks percentage of KRA test was also significantly higher in the pass group as compared to the fail group being $67 \& 47 \%$ respectively. Therefore, the statistical comparison also demonstrated significant $(P<0.0005)$ difference for STM \&KRA among pass and fail students.

\section{c) Correlation between STM \& KRA}

Table II, demonstrates result of Pearson correlation between marks obtained in STM and KRA tests of the students. It represents significant difference in both the tests at the level of 0.01 . Further, it has been observed that 31 out of 74 students who appeared in $1^{\text {st }}$ and $2^{\text {nd }}$ cycle of STM test gave correct answer in $1^{\text {st }}$ cycle but unexpectedly answered incorrectly in 2nd cycle, for the same question, just after $5 \mathrm{~min}$. 
Farhan Muhammad Qureshi, Muhammad Abdul Azeem, Mehwish Ejaz, Minal Marvi, Sana Soomro, Layla Hasina, Shanila Khan

According to Table III, out of 31 students, one of them gave 6 incorrect answers in cycle-2 showing extreme problem in STM, representing $1 \%$ of total $(n=31)$ students.While,14 of them gave only 1 incorrect answer showing least problem in STM, representing $19 \%$ of the total $(n=31)$ students.

TABLE I: A STATISTICAL COMPARISON OF CLASS ATTENDANCE AMONG PASS \& FAIL STUDENTS OF MIDTERM EXAM AND THEIR MARKS PERCENTAGE OF A TOTAL OF 103 STUDENTS

\begin{tabular}{|l|c|c|}
\hline \multicolumn{1}{|c|}{$\begin{array}{c}\text { Mid Term } \\
\text { Result }\end{array}$} & $\begin{array}{c}\text { Class Atten- } \\
\text { dance \%age } \\
\text { Mean } \pm \text { SE (n) }\end{array}$ & $\begin{array}{c}\text { Mid Term Exam } \\
\text { Marks } \\
\text { Mean } \pm \text { SE (n) }\end{array}$ \\
\hline Passed & $82 \pm 0.79(48)$ & $62.67 \pm 1.05(48)$ \\
\hline P value & $P<0.0005$ & $P<0.0005$ \\
\hline Failed & $75 \pm 1.27(55)$ & $29.73 \pm 1.75(55)$ \\
\hline \multicolumn{3}{|c|}{ Pearson Correlation } \\
\hline $\begin{array}{c}\text { Over All Percentage } \\
\text { of Attendance } \\
\text { Mean } \pm \text { SD (n=103) }\end{array}$ & $\begin{array}{c}\text { Over All Percent- } \\
\text { age of Marks } \\
\text { Mean } \pm \text { SD } \\
(\mathbf{n}=103)\end{array}$ & $\begin{array}{c}\text { (significant at } 0.01 \\
\text { level; 2-tailed) }\end{array}$ \\
\hline $78.472 \pm 0.839$ & $45.083 \pm 1.940$ & .531 \\
\hline
\end{tabular}

Fig I: Comparison of the Post Mid-Term Exam's Average Marks obtained by Pass \& Fail students in Short Term Memory (STM) \& Knowledge Retention Ability (KRA) Tests

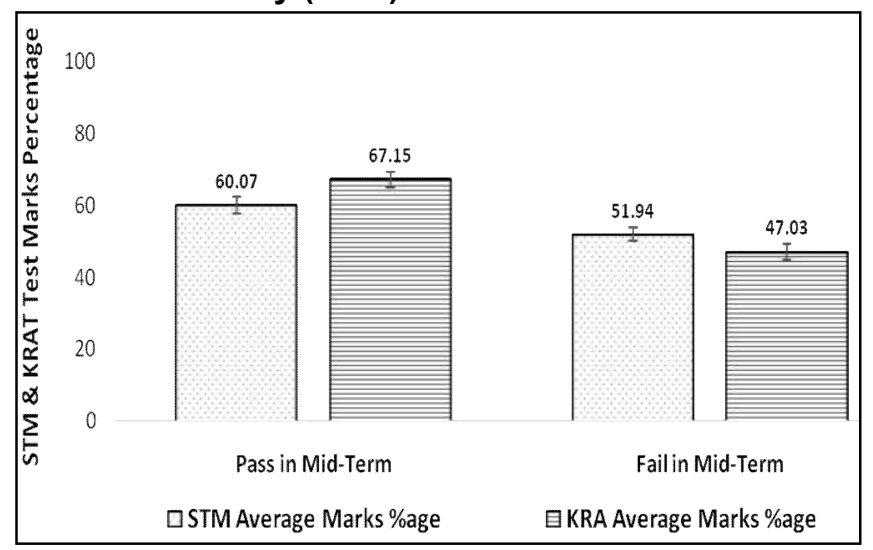

TABLE II: STATISTICAL COMPARISON \& CORRELATION OF SHORT TERM MEMORY VS KNOWLEDGE RETENTION ABILITY
TABLE III: NUMBER AND PERCENTAGE OF STUDENTS WHO ANSWERED INCORRECTLY FOR THE SAME QUESTION IN CYCLE 2 BUT WERE CORRECT IN EARLIER CYCLE 1

\begin{tabular}{|c|c|c|}
\hline \multirow{2}{*}{$\begin{array}{c}\text { Number of } \\
\text { Wrong } \\
\text { Answers }\end{array}$} & \multicolumn{2}{|c|}{$\begin{array}{c}\text { 31 out of 74 Students who gave } \\
\text { wrong answers in Cycle 2 }\end{array}$} \\
\cline { 2 - 3 } & Number & Percentage \\
\hline 1 & 14 & 19 \\
\hline 2 & 11 & 15 \\
\hline 3 & 4 & 5 \\
\hline 5 & 1 & 1 \\
\hline 6 & 1 & 1 \\
\hline
\end{tabular}

\section{DISCUSSION}

Memory, broadly speaking, refers to our ability to retain information. It reflects our conscious awareness. Memory tests are powerful tools for the improvement of long-term retention of knowledge ${ }^{9}$.Memory related to any kind of knowledge can prey to the process of forgetfulness. STM is fleeting and allows us to retain items for a short period of time. It may also forms the basis of our long-term memory and the retention of knowledge, as its contents endure only as long as we are paying attention towards learning, being active learner.

Researchers of the present study hypothesized that a better class attendance is the basis for better learning and getting good marks in exam and STM can help in the ability to retain knowledge. Thus, these were compared among pass and fail students of a mid-term test.

According to the obtained results it is revealed that absenteeism is associated with poor exam performance and the students who attended lectures regularly declared successful and there was a statistically significant difference between percentage of attendance and marks obtained in mid-term exams. This finding is consistent with the results study conducted in Spain ${ }^{12}$. They have shown that there is a positive correlation between attendance and academic assessment. Thus, attendance does matter for academic achievement. In this connection, it is to be noted that those students who attend lectures

\begin{tabular}{|l|c|c|c|c|c|}
\hline \multirow{2}{*}{ Type of Test } & \multicolumn{4}{|c|}{ Statistics Related to obtained Marks by Students } \\
\cline { 2 - 5 } & $\begin{array}{c}\text { Number of } \\
\text { students (n) }\end{array}$ & Mean & $\begin{array}{c}\text { Std. Error } \\
\text { Mean }\end{array}$ & $\begin{array}{c}\text { t-Test } \\
\text { (2-tail) }\end{array}$ & $\begin{array}{c}\text { Pearson's Correlation } \\
\text { (Sig. 2-tails) }\end{array}$ \\
\hline Short Term Memory (STM) & 74 & 78.53 & 1.363 & $.000^{*}$ & \multirow{2}{*4.433^{**}}{} \\
\hline Knowledge Retention Ability(KRA) & 74 & 77.57 & 1.570 & & \\
\hline${ }^{*}$ Confidence level 95\%; ${ }^{* *}$ Correlation significant at the level of 0.01 \\
\hline
\end{tabular}


more frequently on average, and receive higher grades, indicate their inherent motivation to concentrate during classes. However, attendance, even though critical to the learning process, is not the single most important factor ${ }^{10}$. In this connection, the factors like active learning, involvement in extracurricular activities $^{14}$, students' motivation, and level of engagement ${ }^{11}$ are also important.

Further, the students showed better results in STM \& KRA test in pass group showing statistically significant difference and significant correlation with failed group. It indicates that KRA of students who passed the mid-term test was better than the fail students and the KRA of those students having better STM scores was also better. It is however suggested that such testing can be applied in regular teaching programs repeatedly, as also suggested earlier ${ }^{9}$.In addition, the methodology used in the present study to conduct 3-cycles repetition of test, is good for testing the learning ability and retention of knowledge.

Another important aspect of learning found in the present study relates with the problem of STM retrieval. As per results of this study, about $42 \%$ of total students who gave incorrect answers in $2^{\text {nd }}$ cycle of STM test after answering correctly in its $1^{\text {st }}$ cycle. In this respect, it is suggested that the problem is in the retrieval of correct information/knowledge during $2^{\text {nd }}$ cycle of STM. It may be speculated that two things might be involved in this problem: First, implicit memory that is referred as hidden memory and uses past experiences to remember things without thinking about them ${ }^{15}$.Second, the involved approach to learn. This shows that the participants performed implicit learning without being conscious of it. Therefore, it is suggested that many academic tasks does require a substantial amount of students' attention and mental effort, being an active listener ${ }^{16}$ during the learning process. This has been proclaimed by other researchers as well that inability to regulate attention is directly related to student's academic performance ${ }^{17}$. Further, long \& short term retention of knowledge does not compromise even if course format is changed ${ }^{18}$. In order to avoid information / knowledge drain, the learners or students need to use and apply a range of cognitive skills which requires both attention and memory ${ }^{19}$.

\section{CONCLUSION}

The present study has reported a positive correlation between attendance and marks percentage in examination. It is suggested that the educational process should be tailored to shift learning information stored in the brain and retrievable over a long period of time through active learning, resulting in more efficient learning and avoid memory drain problem. In this respect class attendance and repetitive testing is the important facilitator of academic success.

\section{Contributors}

All authors contributed to the concept of study, data analysis, editing, revising and final paper approval \& all of them also meet the criteria for authorship.

\section{ACKNOWLEDGEMENT}

We would like to appreciate the permission given by the research \& ethical committee of United Medical \& Dental College, for this study. Acknowledgement is also due for the students who participated in this study of STM \& KRAT during $1^{\text {st }}, 2^{\text {nd }} \& 3^{\text {rd }}$ cycles.

\section{Role of funding}

Study did not require any funding and the employer had no role in the design, analysis and interpretation of study results. Authors are the faculty members at Bahria University Medical \& Dental College, Karachi and United Medical \& Dental College, Karachi, Pakistan.

\section{Competing interests}

We declare to have no competing interests.

\section{Ethical Approval}

Ethical approval was obtained through United Medical \& Dental College.

\section{REFERENCES}

1. Lindsey RV, Shroyer JD, Pashler H, Mozer MC. Improving students' long-term knowledge retention through personalized review. Psychol Sci. 2014 Mar;25(3):639-47.

2. Ferreira JJ, Maguta L, Chissaca AB, Jussa IF, Abudo SS. Cohort study to evaluate the assimilation and retention of knowledge after theoretical test in undergraduate health science. Porto Biomed J. 2016;1(5):181-5.

3. Revlin, R. (2011) Short-Term Memory and Working Memory. Cognition Theory and Practice. Worth Publishers. Chapter 5, pg 119-149 Retrieved from: http://www.macmillanhighered.com/ Catalog/uploadedFiles/Content/Worth/Product/ About/Look_Inside/Revlin,_Cognition_1e/ Revlin1e_Chapter\%205.pdf

4. Gathercole SE, Pickering SJ, Ambridge B, Wearing $\mathrm{H}$. The structure of working memory from 4 to 15 years of age. Dev psychol. 2004 Mar;40 (2):177-90.

5. Gathercole SE, Alloway TP. Working memory and learning: A practical guide for teachers. 2008. Sage Publishing.

6. Larsen DP, Butler AC, Roediger $\mathrm{HL} 3^{\text {rd }}$. Test-enhanced learning in medical education. Med Educ. 2008;42(10):959-66.

7. Roediger HL, Karpicke JD. Test-enhanced 
learning: Taking memory tests improves long-term retention. Psychol Sci. 2006;17(3):249-55.

8. Custers EJ. Long-term retention of basic science knowledge: a review study. Adv Health Sci Educ Theory Pract. 2010;15(1):109-28.

9. Roediger $\mathrm{HL} 3^{\text {rd }}$, Karpicke JD. The power of testing memory: Basic research and implications for educational practice. Perspect Psychol Sci. 2006;1(3):181-210.

10. Cohall DH, Skeete D. The impact of an attendance policy on the academic performance of first year medical students taking the Fundamentals of Disease and Treatment course. Caribbean Teaching Scholar. 2012; 2(2):115-23.

11. Credé M, Roch SG, Kieszczynka UM. Class attendance in college: A meta-analytic review of the relationship of class attendance with grades and student characteristics. Rev Educ Res. 2010 Jun;80(2):272-95.

12. Gal B, Busturia I, Garrido C. To be or not to be: the importance of attendance in integrated physiology teaching using non-traditional approaches. BMC Res Notes. 2011;4(1):360.

13. Amini M, Dehghani MR, Kojuri $J$, et al. A qualitative study of factors associated with medical students' academic success. J Social Sci. 2008; 4(4), 347-51.

14. Ali N, Jusoff K, Ali S, et al. The factors influencing students' performance at Universiti Teknologi MARA Kedah, Malaysia. Management Science and Engineering. 2009;3(4):81-90.

15. Zimmermann, K. A. Implicit Memory: Definition and Examples. Live Science, 2014. Web. 2 Feb. 2017. Available online at: http:// www.livescience.com/43353-implicit-memory.html

16. Cuseo J, Fecas V, Thompson A. Thriving in College and Beyond: Research based strategies for academic success and personal development. 2007; IA: Kendall/Hunt Publishing.

17. Beilock SL, Decaro MS. From poor performance to success under stress: working memory, strategy selection, and mathematical problem solving under pressure. J Exp Psychol Learn Mem Cogn. 2007;33(6):983-98.

18. Faught BE, Law M, Zahradnik M. How Much Do Students Remember Over Time? Longitudinal Knowledge Retention in Traditional Versus Accelerated Learning Environments. Toronto: Higher Education Quality Council of Ontario; 2016.

19. Watson SMR, Gable RA. Using knowledge of student cognition to differentiate instruction" Reaching every learner: Differentiating instruction in theory and practice. 2010. Available at: http:// www.learnnc.org/lp/editions/every-learner/6693? ref=blog

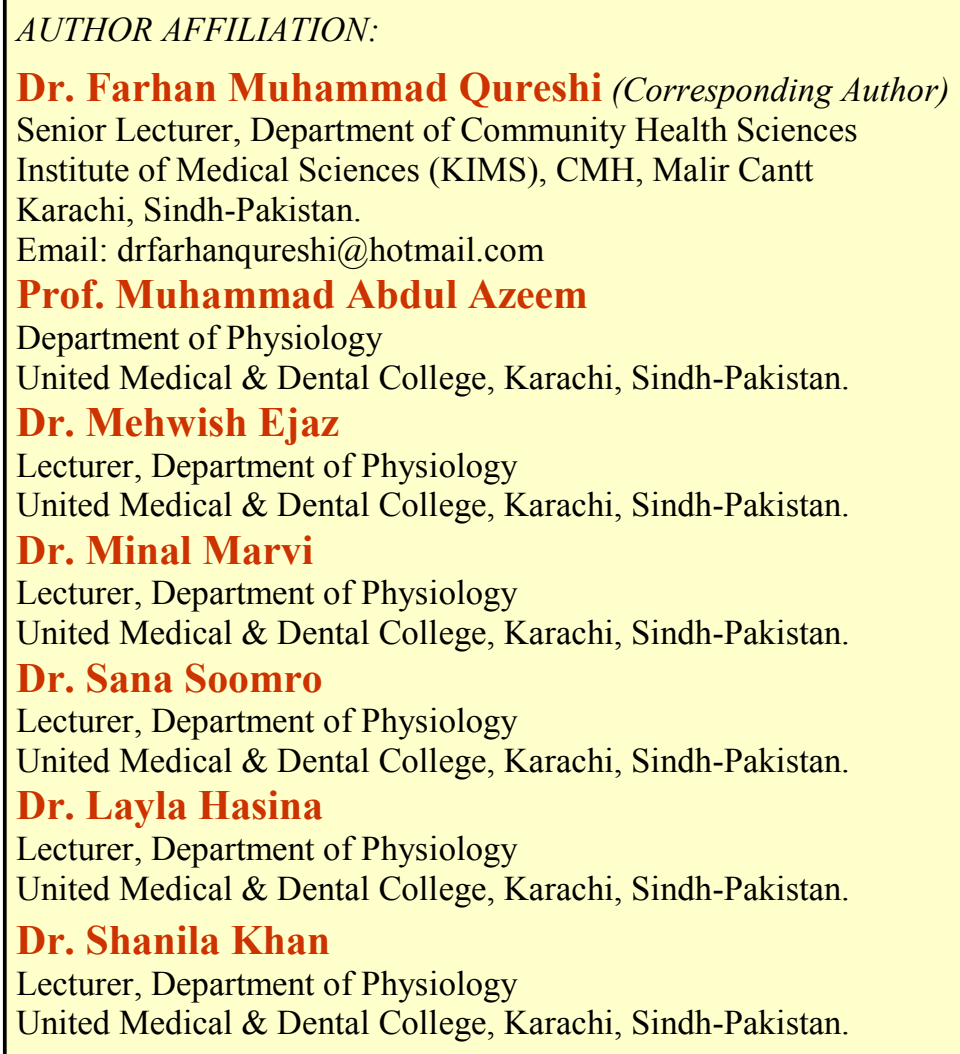

